\title{
Sequence analysis of coding DNA fragments of pfcrt and pfmdr-1 genes in Plasmodium falciparum isolates from Odisha, India
}

\author{
Sasmita Kumari Das Sutar ${ }^{1}$, Bhavna Gupta ${ }^{2}$, Manoranjan Ranjit ${ }^{1}$, Shantanu Kumar Kar ${ }^{1}$, Aparup Das²/+ \\ ${ }^{1}$ Regional Medical Research Center, Indian Council of Medical Research, Bhubaneswar, Odisha, India \\ ${ }^{2}$ National Institute of Malaria Research, Indian Council of Medical Research, Dwarka, New Delhi, India
}

The global emergence and spread of malaria parasites resistant to antimalarial drugs is the major problem in malaria control. The genetic basis of the parasite's resistance to the antimalarial drug chloroquine (CQ) is well-documented, allowing for the analysis of field isolates of malaria parasites to address evolutionary questions concerning the origin and spread of CQ-resistance. Here, we present DNA sequence analyses of both the second exon of the Plasmodium falciparum CQ-resistance transporter (pfcrt) gene and the 5' end of the P. falciparum multidrug-resistance 1 (pfmdr-1) gene in $40 \mathrm{P}$. falciparum field isolates collected from eight different localities of Odisha, India. First, we genotyped the samples for the pfcrt K76T and pfmdr-1 N86Y mutations in these two genes, which are the mutations primarily implicated in CQ-resistance. We further analyzed amino acid changes in codons 72-76 of the pfcrt haplotypes. Interestingly, both the K76T and N86Y mutations were found to co-exist in 32 out of the total 40 isolates, which were of either the CVIET or SVMNT haplotype, while the remaining eight isolates were of the CVMNK haplotype. In total, eight nonsynonymous single nucleotide polymorphisms (SNPs) were observed, six in the pfcrt gene and two in the pfmdr-1 gene. One poorly studied SNP in the pfcrt gene (A97T) was found at a high frequency in many $\mathrm{P}$. falciparum samples. Using population genetics to analyze these two gene fragments, we revealed comparatively higher nucleotide diversity in the pfcrt gene than in the pfmdr-1 gene. Furthermore, linkage disequilibrium was found to be tight between closely spaced SNPS of the pfcrt gene. Finally, both the pfcrt and the pfmdr-1 genes were found to evolve under the standard neutral model of molecular evolution.

Key words: antimalarial resistance - Plasmodium falciparum - pfcrt - pfmdr-1 - Odisha - India

Malaria is a highly infectious disease, resulting in approximately 300 million new cases and causing approximately 0.8 million deaths every year across the globe (WHO 2009). Most malaria-related deaths are caused by Plasmodium falciparum, a protozoan parasite that completes its sexual life cycle in mosquito and its asexual life cycle in humans. While chloroquine (CQ) was once considered to be the gold standard drug used to treat malaria, the emergence and spread of CQ-resistance in P. falciparum over the last 50 years has significantly exacerbated global malaria control programs (Wongsrichanalai et al. 2002). Both the mechanisms of CQ action and the genetic basis of CQ-resistance have been well-studied in $P$. falciparum. The $P$. falciparum multidrug-resistance 1 ( pfmdr-1) gene located on chromosome 5 of $P$. falciparum was initially implicated in CQ-resistance (Wilson et al. 1989, Foote et al. 1990). However, the high correlation of a mutation in a transporter gene located on chromosome 7, called P. falciparum CQ-resistance transporter ( $p f c r t$ ) and the corresponding CQ response (Fidock et al. 2000, Sidhu et al. 2002) has led to a better understanding of the genetic basis of CQ-resistance in malaria parasites. Spe-

+ Corresponding author: aparup@mrcindia.org

Received 14 July 2010

Accepted 4 November 2010 cifically, an amino acid mutation in codon 76 of the $p f c r t$ gene is strongly correlated with CQ-resistance from both in vitro and in vivo studies (Fidock et al. 2000, Sidhu et al. 2002) and has thus become the genetic marker to determine CQ-resistance in P. falciparum isolates. Similar studies of the $p f m d r-1$ gene, which encodes a P-glycoprotein, have uncovered interesting details; however a direct association between mutations in this gene and CQ-resistance has not been established (Basco \& Ringwald 1998, Reed et al. 2000, Le Bras \& Durand 2003). In many cases, the N86Y mutation in the $p f m d r-1$ gene was found to be either compensating for mutations in the pfcrt gene, or to have a role in CQ-resistance by itself (Adagu \& Warhurst 2001, Babiker et al. 2001, Djimdé et al. 2001). Hence, both pfcrt K76T and pfmdr-1 N86Y mutations are now used as genetic markers to determine CQ-resistance in P. falciparum isolates.

While much genetic information is known about these two genes, the estimation of DNA sequence variation in the nucleotide regions flanking the 76th and 86th amino acid positions of the $p f c r t$ and $p f m d r-1$ genes, respectively, is generally uncharacterized. Haplotype profiles of populations based on mutations in the five amino acids adjacent to the known K76T mutation site (codons 72-76 in the pfcrt gene) have been analyzed to study the origin and migration history of CQ-resistance in $P$. falciparum. India is one of the malaria-endemic countries that have a relatively high incidence of CQ-resistant $P$. falciparum cases (Vathsala et al. 2004, Mittra et al. 2006, Singh et al. 2009, Mixson-Hayden et al. 2010). Several studies have reported haplotypic data on the pfcrt gene 
related to five amino acid changes (72nd-76th positions) and the frequency of the N86Y mutation in the $p f m d r-1$ gene (Fidock et al. 2000, Djimdé et al. 2001, Vathsala et al. 2004). Additional observations on microsatellite variations in and around the pfcrt gene and the evolutionary history of this gene in India have also been reported (Das \& Dash 2007, Mixson-Hayden et al. 2010). However, evolutionary analyses of the DNA sequences of these two genes have not been performed. To understand the effect of additional mutations in these genes and the evolutionary interactions among these different mutations, we carried out studies in Odisha (earlier known as Orissa), a southeastern state of India (Fig. 1), that has the highest number of $P$. falciparum malaria cases in India, and where CQ-resistance among $P$. falciparum field isolates is highly prevalent (Singh et al. 2009). Therapeutic efficacy studies of $P$. falciparum field isolates in different localities of Odisha revealed that the state is under a strong belt of CQ-resistant malaria (Ranjit et al. 2009). This study is an initiative to map pfcrt haplotypes and to identify new mutations in the pfcrt and the $p f m d r-1$ genes, in order to infer the evolutionary history of these two genes in Odisha.

\section{SUBJECTS, MATERIALS AND METHODS}

Forty field-isolates collected from eight different locations of Odisha (Fig. 1) constitute the samples for this study. The total number of samples collected from each location is depicted in Fig. 1. The samples were collected from adult patients with malarial symptoms attending the local primary health centres (PHCs) in the eight locations. The Ethical Committee of the Regional Medical Research Center, Bhubaneswar, Odisha, has approved the study protocols used here and informed consents were obtained from all the patients prior to sample collection. To diagnose malaria, both thin and thick smears from finger-prick blood samples of malaria-sympto- matic patients attending the PHCs were Giemsa-stained and examined microscopically. Approximately $1 \mathrm{~mL}$ of venous blood was added to a tube $1.8 \mathrm{mg} / \mathrm{mL}$ after containing ethylenediamine tetraacetic acid (EDTA) from the patients who were confirmed to be positive for the presence of $P$. falciparum parasites following microscopic examination. Genomic DNA of $P$. falciparum was isolated from $100 \mu \mathrm{L}$ of venous blood through lysis of erythrocytes in lysis buffer ( $10 \mathrm{mM}$ Tris- $\mathrm{HCl}, 0.1 \mathrm{M}$ EDTA pH 8.0, $20 \mu \mathrm{g} / \mathrm{mL}$ RNAase A, 0.5\% sodium dodecyl sulfate and $100 \mu \mathrm{g} / \mathrm{mL}$ proteinase $\mathrm{K}$ ) at $55^{\circ} \mathrm{C}$ for 16 $\mathrm{h}$ followed by phenol-chloroform extraction and ethanol precipitation (Sambrook \& Russell 2001).

Because mutations in the 76th and 86th positions in the $p f c r t$ and $p f m d r-1$ genes, respectively, are considered to be the determinants of CQ-sensitivity or resistance, we genotyped all 40 isolates for the well-characterized $p f c r t$ K76T and $p f m d r-1$ N86Y mutations. To analyze the pfcrt gene, we amplified a 264-bp region of the second exon (Fig. 2) that contains the K76T polymorphism using the primer set 5'-GGCTCACGTTTAGGTGGA-3' and 5'-TGAATTTCCCTTTTTATTTCCAAA-3,' as described by Vathsala et al. (2004). To establish the presence of the K76T mutation, this polymerase chain reaction (PCR) product from a $P$. falciparum isolate was enzymatically digested with $A p o$ I. If restriction digestion took place and divided the PCR product into two fragments (128 and $136 \mathrm{bp}$ ), the isolate was considered CQsensitive (Vathsala et al. 2004). Similarly for the $p f m d r-1$ gene, the primer pair 5'-ATGGGTAAAGAGCAGAAAGA-3' and 5'-AACGCAAGTAATACATAAAGTCA-3' was used to amplify a 603-bp fragment at the extreme 5, end of the gene (Vathsala et al. 2004) (Fig. 2) that contains the N86Y mutation. This PCR product subsequently underwent restriction digestion with $A f l I I I$. The amplified PCR product of a $P$. falciparum isolate digested into two fragments (253 and $350 \mathrm{bp}$ ) indicated the presence of the

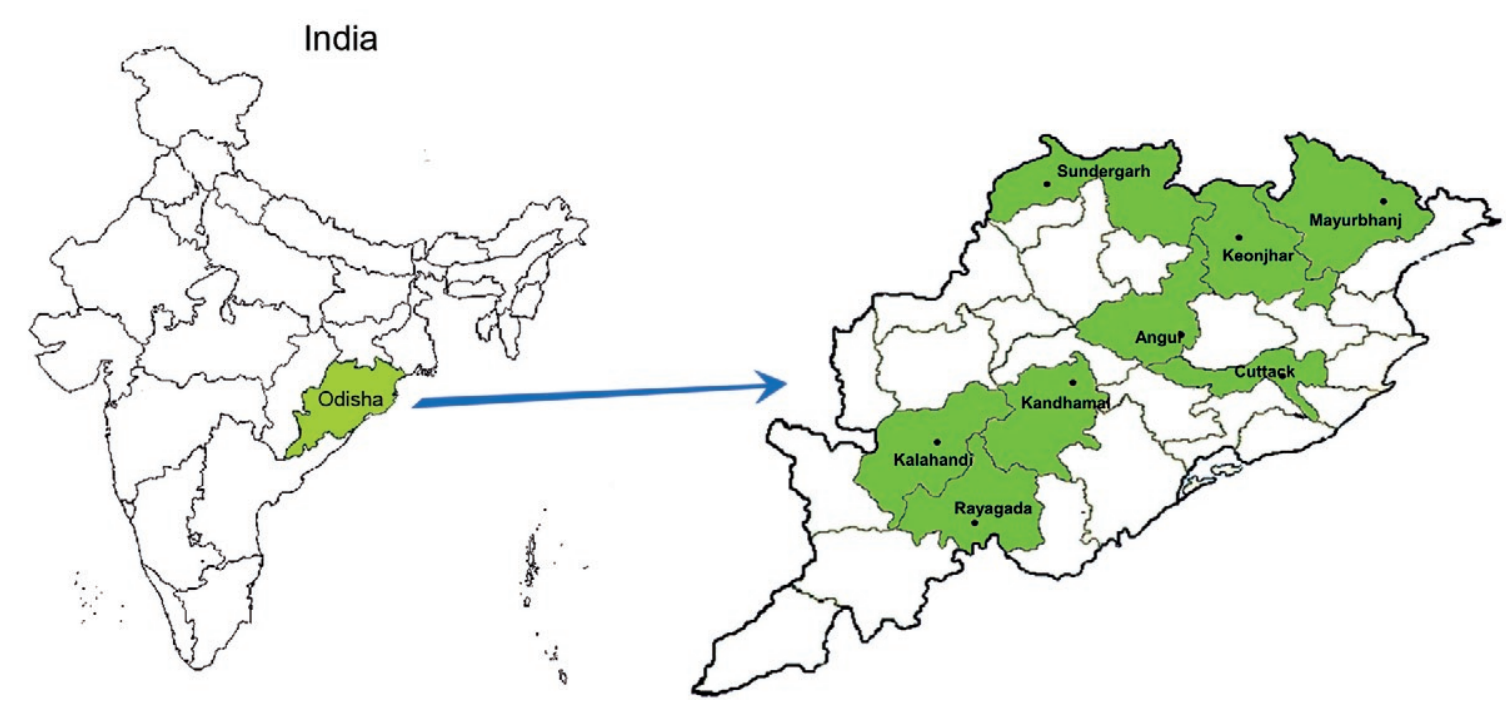

Fig. 1: map of India indicating Odisha and location of the eight places from where samples of Plasmodium falciparum isolates have been collected. The sample size from each location is: Sundergarh, 7; Mayurbhanj, 6; Keonjhar, 6; Angul, 5; Kandhamal, 5; Rayagada, 5; Kalahandi, 2; Cuttack, 4. 

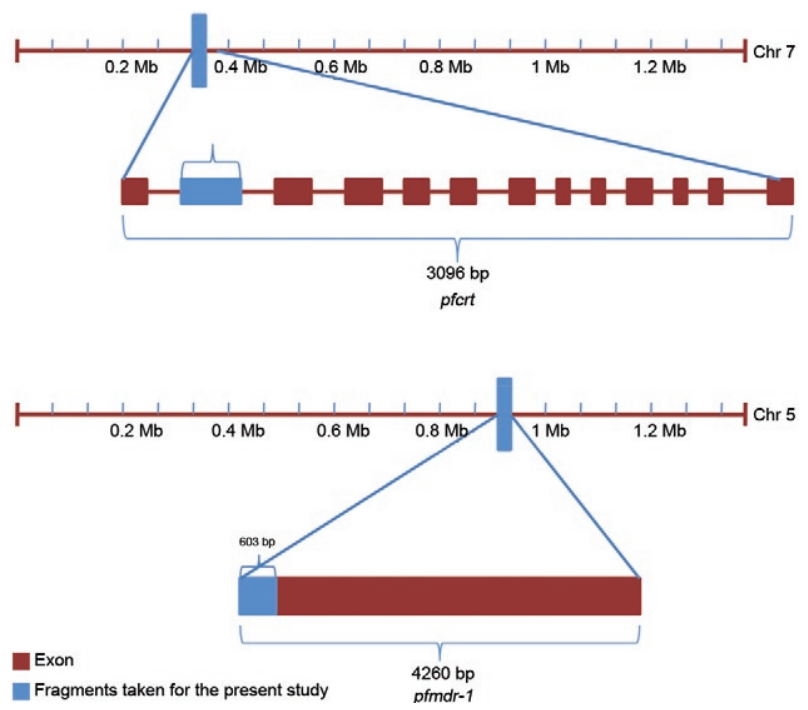

Fig. 2: locations of Plasmodium falciparum chloroquine-resistance transporter ( $p f c r t)$ and $P$. falciparum multidrug-resistance 1 ( $\mathrm{pfm}$ $d r-1)$ genes on their respective chromosomes and of the genetic regions taken for sequencing.

$\mathrm{N}$ to $\mathrm{Y}$ mutation in the 86th codon position of $p f m d r-1$, whereas PCR products from CQ-sensitive isolates were resistant to digestion (Vathsala et al. 2004).

To determine the CQ-resistant haplotypes in the $p f c r t$ gene based on mutations in codons 72-76 and to uncover novel single nucleotide polymorphisms (SNPs), we sequenced the PCR products of pfcrt and pfmdr-1 genes (as amplified). Undigested amplified products of all 40 isolates were purified with Exo-SAP (Fermentas Life Sciences) at $37^{\circ} \mathrm{C}$ for $60 \mathrm{~min}$ and at $85^{\circ} \mathrm{C}$ for an additional $15 \mathrm{~min}$. For each sequencing reaction, we used $2-4 \mu \mathrm{L}$ of the purified PCR product and sequencing was performed by the cycle sequencing method using Big Dye Terminator chemistry on an ABI 3730XL automated DNA sequencer at the National Institute of Malaria Research, New Delhi. Each fragment was sequenced in both the forward and reverse directions (2X coverage) and assembled and edited using the SeqMan program (DNASTAR, Madison, WI, USA). Homologous DNA fragments were aligned using the program MegAlign of DNASTAR, with the ClustalW algorithm. Haplotypes were inferred based on the SNPs present in these DNA fragments from multiple sequence alignments of both gene fragments. The sequences are deposited in GenBank with accessions HQ287007-HQ287086. Estimations of diversity parameters, such as haplotype diversity (Hd) (Nei 1987) and two measures of nucleotide diversities, $\theta_{w}$ and $\pi$ (Watterson 1975, Tajima 1983), were calculated using the program DnaSP, version 5.00.02 (Rozas et al. 2003). While estimation of $\pi$ is based on the mean number of pair-wise nucleotide differences in a sample (Tajima 1983), estimation of $\theta_{w}$ is based on the number of segregating mutations (Watterson 1975). To test whether the observed allele frequency spectrum was in accordance with the expectations from the neutral model of molecu- lar evolution in each DNA fragment, Tajima's $D$ was calculated, which is based on the normalized discrepancy between $\pi$ and $\theta_{w}$ (Tajima 1989). We also calculated other measures of neutrality, such as Fu and Li's $D^{*}$ (FLD) and Fu and Li's $F^{*}$ (FLF) (Fu \& Li 1993). The FLD and FLF (Fu \& Li 1993) rely on the differences between the number of polymorphic sites in external branches (polymorphisms unique to an existing sequence) and number of polymorphic sites in internal phylogenetic branches (polymorphisms shared by existing sequences) (Zhang $\&$ Ge 2007). For both tests, negative values indicate an excess of low-frequency polymorphisms, while positive values indicate an excess of intermediate polymorphisms (Tajima 1989, Fu \& Li 1993, Fu 1997). Furthermore, the number of nonsynonymous substitutions per nonsynonymous site $(\mathrm{dN})$ and the number of synonymous substitutions per synonymous site (Nei \& Gojobori 1986) were estimated and a z-test was performed to estimate the $p$ value using the program MEGA, version 4 (Tamura et al. 2007). To determine whether any of the eight total SNPs (present in both the genes) are associated with each other, both inter and intragenic linkage disequilibrium (LD) were estimated with the $\mathrm{r}^{2}$ values, using the program Haploview (Barrett et al. 2005).

\section{RESULTS}

A total of 40 P. falciparum isolates of unknown CQsensitivity were analyzed for the presence of the K76T and N86Y mutations in the $p f c r t$ and $p f m d r-1$ genes, respectively. For the $p f c r t$ gene, only eight PCR samples produced the expected 128 and $136 \mathrm{bp}$ amplicon when digested with ApoI, indicating the presence of the wildtype K76 codon, while the remaining 32 isolates resisted enzymatic digestion, indicating the presence of the K76T mutation in these samples (Table I). Similarly, restriction digestion of the $603 \mathrm{bp}$ DNA fragment of pfmdr-1 with AflIII produced two fragments (253 and $350 \mathrm{bp}$ ) in only those 32 isolates that also possessed the K76T mutation, indicating the presence of the N86Y mutation in these isolates (Table I).

The presence of these two mutations was further confirmed in all 40 isolates through DNA sequencing of the amplified fragments from these two genes. In our analysis of both the $p f c r t$ and $p f m d r-1$ genes, we sequenced 867 nucleotides in each of the 40 P. falciparum isolates from Odisha, totaling 34,680 nucleotide bp sequenced with $2 \mathrm{X}$ coverage. Separate sequence alignment for both genes revealed six SNPs in the pfcrt gene and two SNPs in the $p f m d r-1$ gene. The number of haplotypes identified varied between the $p f c r t$ and $p f m d r-1$ genes, with four in the $p f c r t$ gene and three in the $p f m d r-1$ gene. Sequenced fragments of both genes were translated into amino-acid sequences. Five point mutations were observed in codons $72,74,75,76$ and 97 of the pfcrt amino acid sequence and two point mutations were observed in codons 86 and 184 position of $p f m d r-1$ (Table I). No synonymous (or silent) substitutions were observed, indicating that all the eight SNPs detected in both the genes were nonsynonymous (amino acid-changing nucleotide substitutions). The N86Y mutation and wildtype Y184 codon were found together in 32 P. falciparum isolates, 
while the Y184F mutation was present in two isolates that had the N86Y mutation in the $p f m d r-1$ gene. Although several haplotypes have been reported to exist due to the presence of different amino acids in codons 72-76 of the pfcrt gene, only three haplotypes (CVIET, SVMNT and CVMNK) were found in the presently studied Odisha samples. We identified the CVIET haplotype the most frequently $(67.5 \%)$, followed by the CVMNK (20\%) and SVMNT (12.5\%) haplotypes.

The two estimates of nucleotide diversity, as measured by $\pi$ and $\theta_{w}$, were found to be variable for both the genes examined ( $p f c r t$ and $p f m d r-1$ ) (Table II). In general, the pfcrt gene showed higher genetic diversity than the $p f m d r-1$ gene (Table II). It is clear from Table
II that the $\pi$ values in both the genes are slightly higher than the $\theta_{w}$ values, indicating a greater number of intermediate frequency mutations. We also conducted three tests of neutrality and none of them showed statistically significant results to indicate any departure from neutrality (Table II). However, in general, the data signifies that both genes are evolving under the standard neutral model of molecular evolution in the population sample of Odisha. All the mutations detected in this study were nonsynonymous; therefore, only $\mathrm{dN}$ values, $0.011 \pm 0.006$ for $p f c r t$ and $0.001 \pm 0.001$ for $p f m d r-1$ genes, could be estimated and these were found to be statistically significantly different from the silent polymorphisms (not detected in the study) in the case of the

TABLE I

Nucleotide sequences and amino acid residues of codons 72-76 of the Plasmodium falciparum chloroquine-resistance transporter $(p f c r t)$ and 86 and 184 codons of $P$. falciparum multidrug-resistance $1(p f m d r-1)$ genes

\begin{tabular}{|c|c|c|c|c|c|c|c|}
\hline \multirow[b]{2}{*}{ Position of SNP } & \multicolumn{5}{|c|}{ pfcrt gene fragment } & \multicolumn{2}{|c|}{ pfmdr-1 gene fragment } \\
\hline & 72 & 74 & 75 & 76 & 97 & 86 & 184 \\
\hline Wild genotype & 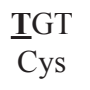 & $\underset{\text { Met }}{\text { AT } \underline{G}}$ & $\underline{\mathrm{A}} \underline{\mathrm{A}}_{\mathrm{T} n}^{\mathbf{T}}$ & $\underset{\text { Lys }}{\mathrm{A}}$ & $\begin{array}{c}\mathrm{C} \underline{\mathrm{A} C} \\
\mathrm{His}\end{array}$ & $\frac{\mathbf{A} A T}{A s n}$ & $\begin{array}{l}\text { TÁ } \\
\text { Tyr }\end{array}$ \\
\hline Isolates with wild genotype (n) & 35 & 13 & 13 & 8 & 30 & 8 & 38 \\
\hline Mutant genotype & $\underline{\mathbf{A}}_{\text {Ser }}$ & $\begin{array}{c}\mathrm{AT} \underline{\mathbf{T}} \\
\mathrm{Ile}\end{array}$ & $\frac{\underline{\mathbf{G A}}}{\text { Glu }}$ & $\begin{array}{c}\mathrm{AC} \underline{\mathrm{CA}} \\
\mathrm{Th} \mathrm{r}\end{array}$ & $\begin{array}{c}\text { C } \underline{\mathbf{T C}} \\
\text { Leu }\end{array}$ & $\begin{array}{c}\underline{\mathbf{T A T}} \\
\text { Tyr }\end{array}$ & $\begin{array}{l}\text { TTT } \\
\text { Phe }\end{array}$ \\
\hline Isolates with mutations (n) & 5 & 27 & 27 & 32 & 10 & 32 & 2 \\
\hline
\end{tabular}

the single nucleotide polymorphisms (SNP) in each codon has been indicated as bold and underlined nucleotide.

TABLE II

Details of Plasmodium falciparum chloroquine-resistance transporter ( $p f c r t$ ) and $P$. falciparum multidrug-resistance 1 ( pfmdr-1) genes fragments and population genetic parameters in P. falciparum isolates of Odisha, India

\begin{tabular}{|c|c|c|c|}
\hline \multicolumn{2}{|l|}{ Genes } & $\begin{array}{c}p f c r t \\
(308526-311620) \\
3096 \mathrm{bp}\end{array}$ & $\begin{array}{c}\text { pfmdr-1 } \\
(957885-962144) \\
4260 \mathrm{bp}\end{array}$ \\
\hline \multicolumn{2}{|l|}{ Isolates (n) } & 40 & 40 \\
\hline \multicolumn{2}{|c|}{ Size of the fragment (bp) } & 264 & 603 \\
\hline \multicolumn{2}{|l|}{ Nucleotide positions } & $308619-308883$ & $957885-958487$ \\
\hline \multicolumn{2}{|l|}{ SNPs (n) } & 6 & 2 \\
\hline \multicolumn{2}{|l|}{ Haplotypes (n) } & 4 & 3 \\
\hline \multicolumn{2}{|l|}{ Haplotype diversity } & 0.719 & 0.344 \\
\hline \multirow[t]{2}{*}{ Nucleotide diversity } & $\theta$ & 0.00541 & 0.00078 \\
\hline & $\pi$ & 0.00866 & 0.00071 \\
\hline \multicolumn{4}{|c|}{ Tests of neutrality } \\
\hline \multicolumn{2}{|l|}{ Tajima's $D$} & 1.6583 & -0.1789 \\
\hline \multicolumn{2}{|l|}{$\mathrm{Fu}$ and Li's $D^{*}$} & 1.1919 & 0.77124 \\
\hline \multicolumn{2}{|l|}{ Fu and Li's $F^{*}$} & 1.5621 & 0.57422 \\
\hline
\end{tabular}

SNP: single nucleotide polymorphisms. 


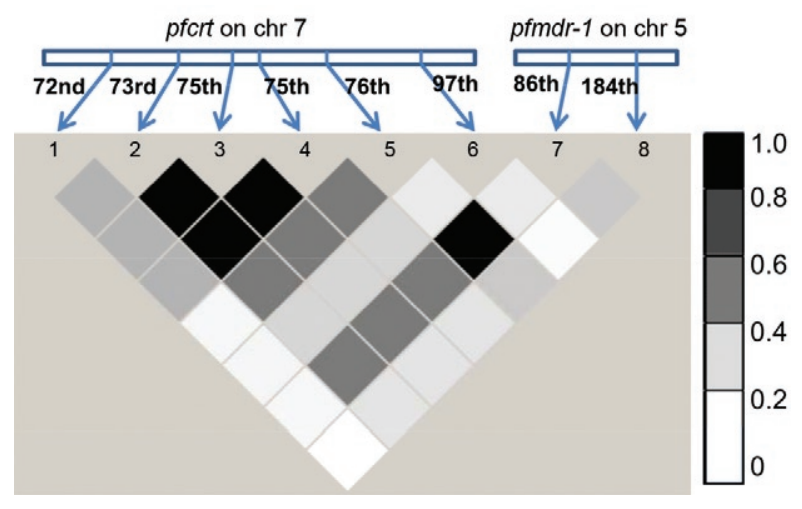

Fig. 3: linkage disequilibrium (LD) plot $\left(\mathrm{r}^{2}\right)$ between 28 possible pairs of single nucleotide polymorphisms (SNPs) in Plasmodium falciparum chloroquine-resistance transporter ( $p f c r t)$ and $P$. falciparum multidrug-resistance 1 ( $p f m d r-1$ ) genes in $P$. falciparum. The strength of statistical significance of LD between a pair of SNPs is represented with the extent of darkness of the boxes (increasing intensity of black color depicts strong LD and the fading grey and white color show week and no LD, respectively).

$p f m d r-1$ gene. However, in the case of the pfcrt gene, no statistically significant difference was obtained (data not shown). Furthermore, LD estimates between all possible pairs of SNPs of both the $p f c r t$ and $p f m d r-1$ genes were determined (Fig. 3). It is evident from Fig. 3 that there are three statistically significant intragenic associations between three SNPs (2 SNPs in codon 74 and 1 SNP in codon 75) in the $p f c r t$ gene and one intergenic association between a SNP of the $p f c r t$ gene (K76T) and a SNP of the $p f m d r-1$ gene (N86Y).

\section{DISCUSSION}

Although the genetic basis of CQ-resistance has been attributed to both the $p f c r t$ and $p f m d r-1$ genes, the $p f c r t$ gene is primarily and directly implicated in CQ-resistance in P. falciparum. This first-ever $p f c r t$ and $p f m d r-1$ DNA fragment sequencing and sequence analysis in India has provided several interesting findings. Specifically, 32 of the 40 P. falciparum isolates possessed both the K76T and the N86Y mutations. These 32 isolates had also acquired either the CVIET or SVMNT, the haplotypes associated with CQ-resistance (Fidock et al. 2000, Vathsala et al. 2004), suggesting that the K76T and the N86Y mutations are the hallmarks of CQ-resistant $P$. falciparum isolates. This is further evidenced from the analyses. It is widely known that both the CVIET and SVMNT haplotypes and the K76T mutation are associated with CQ-resistance in P. falciparum (Fidock et al. 2000, Vathsala et al. 2004). The dominance of the CVIET over the SVMNT haplotype in Odisha contradicts earlier reports of SVMNT prevalence in India (Vathsala et al. 2004, Mixson-Hayden et al. 2010), as well as in Odisha (Pati et al. 2007). However, earlier work (Pati et al. 2007) examined samples from only one particular geographical region of Odisha, whereas in this study we collected data from eight different localities of the state
(Fig. 1), providing a much broader analysis of the genetic pattern of CQ-resistance in P. falciparum in Odisha. Furthermore, in India, a predominance of the SVMNT haplotype (Mixson-Hayden et al. 2010) and a progressive reduction in the number of cases with the rising CVIET haplotype were observed when evaluated for two years (Mixson-Hayden et al. 2010). The present observation of the dominance of the CVIET haplotype might be due to a high proportion of CQ-resistance in Odisha (Ranjit et al. 2009), as the CVIET haplotype is known to be associated with a higher level of CQ-resistance as compared to other haplotypes (Mittra et al. 2006).

The strong association between the occurrence of the K76T and N86Y mutations is one of the interesting findings of this study. Although the involvement of the $\mathrm{pfm}$ $d r-1$ mutation is still under debate, the N86Y mutation has been reported to modulate levels of CQ-resistance to a higher degree when present with the $p f c r t$ K76T mutation (Foote et al. 1990, Djimdé et al. 2001, Mita et al. 2006). Some previous studies have confirmed the association between the N86Y mutation in the $p f m d r-1$ gene and the CQ response (Póvoa et al. 1998, Volkman \& Wirth 1998). However, many other studies have reported a negative correlation between the N86Y mutation and the CQ response (Wellems et al. 1990, Basco et al. 1996, Basco \& Ringwald 1997, McCutcheon et al. 1999). The high prevalence of both the mutations K76T and N86Y in Odisha might be due to the high selection pressure of CQ-resistance, which is a matter of great concern to public health. Further confirmation of the association between the N86Y mutations with CQ-resistance using both in vitro and in vivo assays are needed to initiate appropriate measures to restrict the increasing frequency of these mutations and their spread across the country.

The finding that all new SNPs discovered in this study were nonsynonymous and that the $\mathrm{dN}$ value was significantly higher in the $p f m d r-1$ gene fragment than the pfcrt gene fragment indicate the influence of positive natural selection on the mutations. Besides the wellcharacterized mutations at codons 72-76 in the $p f c r t$ gene and codon 86 in the $p f m d r-1$ gene, two additional mutations (H97L in pfcrt and Y184F in pfmdr-1) were also observed in an appreciable frequency. The H97L has already been reported in the $p f c r t$ gene of CQ-resistant P. falciparum isolates (Fidock et al. 2000, Durrand et al. 2004, Chen et al. 2005) and this amino acid mutation in the pfcrt gene is frequently found in P. falciparum isolates in Odisha, with one-fourth of the presently analyzed isolates found to contain this mutation. Interestingly, this mutation was found in all four isolates from Angul (central Odisha) (Fig. 1) containing the K76T and N86Y mutations and has also been found in the adjoining areas of Angul (Keonjhar, Sundergarh, Cuttack, Kandhamal). The H79L mutation in the pfcrt gene has also reached Rayagada, but at a very low frequency. Although we did not find any strong association of this mutation with any other mutations in the pfcrt and pfmdr-1 genes, the occurrence of this mutation with K76T and N86Y requires further investigation at both the population and functional level. Two isolates with the wildtype K76 codon and the CVMNK haplotype had the Y184F 
mutation in the $p f m d r-1$ gene. The Y184F mutation in the $p f m d r-1$ gene has also been reported to be associated with CQ-resistance in laboratory isolates (Foote et al. 1990), but was unrelated to CQ-resistance in cases of field isolates (Ojurongbe et al. 2007).

Estimation of both the nucleotide diversity parameters $\left(\theta_{w}\right.$ and $\left.\pi\right)$ and Hd were generally higher in the $p f c r t$ gene than the corresponding values in the $p f m d r-1$ gene. In the analysis of a pfcrt gene fragment of only $264 \mathrm{bp}$, six SNPs were observed, which is comparatively higher than that observed in the $p f m d r-1$ gene, which had only two SNPs in a 603 bp gene fragment. This is in contrast to the reported low allelic diversity reported within the pfcrt gene based on microsatellite diversity (Wootton et al. 2002, Mixson-Hayden et al. 2010). High microsatellite diversity in the gene has been previously reported (Vinayak et al. 2006). Although the general observation of selective neutrality was reported for both the genes analyzed in this study, these results are not comprehensive, as we have only sequenced a small DNA fragment within each of these two genes. Sequence analysis of the entire $p f c r t$ and $p f m d r-1$ genes would provide more detailed information on whether these two genes are under the influence of natural selection. Likewise, the LD observed in this study is explained by the physical distance between the SNPs, as the three strongest associations observed were present in the pfcrt gene itself. A broadscale LD study with full sequence information of both the $p f c r t$ and $p f m d r-1$ genes might provide additional meaningful associations.

In conclusion, this DNA sequence dataset of two different gene fragments attributed to CQ-resistance in $P$. falciparum isolates of Odisha indicates that in a highly malaria-endemic region, sufficient evolutionary changes at the molecular level are quite extensive. This is primarily because in a haploid genome with a short generation time (as in case of the malaria parasites), reconstruction of genetic material is fairly easy. This rapid reconstruction not only generates new mutations and high genetic variation, but also opens up the genetic system for natural selection to operate on. This study, although limited to a few isolates and to a limited number of DNA sequences from Odisha, provides preliminary evidence to test the above hypotheses in India, as well as in other malaria-endemic countries.

\section{ACKNOWLEDGEMENTS}

SKDS and MR thank the Director, RMRC Bhubaneswar for constant encouragement and providing necessary laboratory facilities during the course of the work. BG thanks the Indian Council of Medical Research, New Delhi for awarding Junior Research fellowship. Intramural funding from ICMR to $\mathrm{AD}$ is thankfully acknowledged. MR acknowledges the NVBDCP for providing funds.

\section{REFERENCES}

Adagu IS, Warhurst DC 2001. Plasmodium falciparum: linkage disequilibrium between loci in chromosomes 7 and 5 and chloroquine selective pressure in Northern Nigeria. Parasitology 123: 219-224.

Babiker HA, Pringle SJ, Abdel-Muhsin A, Mackinnon M, Hunt P, Walliker D 2001. High-level chloroquine resistance in Sudanese isolates of Plasmodium falciparum is associated with mutations in the chloroquine resistance transporter gene $p f c r t$ and the multidrug resistance gene $\mathrm{pfmdr1.} \mathrm{J} \mathrm{Infect} \mathrm{Dis} \mathrm{183:} \mathrm{1535-1538.}$

Barrett JC, Fry B, Maller J, Daly MJ 2005. Haploview: analysis and visualization of LD and haplotype maps. Bioinformatics 21: 263-265.

Basco LK, de Pecoulas PE, Le Bras J, Wilson CM 1996. Plasmodium falciparum: molecular characterization of multidrug-resistant Cambodian isolates. Exp Parasitol 82: 97-103.

Basco LK, Ringwald P 1997. pfmdrl gene mutation and clinical response to chloroquine in Yaoundé, Cameroon. Trans $R$ Soc Trop Med Hyg 91: 210-211.

Basco LK, Ringwald P 1998. Molecular epidemiology of malaria in Yaoundé, Cameroon. III. Analysis of chloroquine resistance and point mutations in the multidrug resistance 1 ( $p f m d r 1)$ gene of Plasmodium falciparum. Am J Trop Med Hyg 59: 577-581.

Chen N, Wilson DW, Pasay C, Bell D, Martin LB, Kyle D, Cheng Q 2005. Origin and dissemination of chloroquine-resistant Plasmodium falciparum with mutant pfcrt alleles in the Philippines. Antimicrob Agents Chemother 49: 2102-2105.

Das A, Dash AP 2007. Evolutionary paradigm of chloroquine-resistant malaria in India. Trends Parasitol 23: 132-135.

Djimdé A, Doumbo OK, Cortese JF, Kayentao K, Doumbo S, Diourté Y, Dicko A, Su XZ, Nomura T, Fidock DA, Wellems TE, Plowe CV, Coulibaly D 2001. A molecular marker for chloroquine-resistant falciparum malaria. N Engl J Med 344: 257-263.

Durrand V, Berry A, Sem R, Glaziou P, Beaudou J, Fandeur T 2004. Variations in the sequence and expression of the Plasmodium falciparum chloroquine resistance transporter $(p f c r t)$ and their relationship to chloroquine resistance in vitro. Mol Biochem Parasitol 136: 273-285.

Fidock DA, Nomura T, Talley AK, Cooper RA, Dzekunov SM, Ferdig MT, Ursos LM, Sidhu AB, Naudé B, Deitsch KW, Su XZ, Wootton JC, Roepe PD, Wellems TE 2000. Mutations in the P. falciparum digestive vacuole transmembrane protein PfCRT and evidence for their role in chloroquine resistance. Mol Cell 6: 861-871.

Foote SJ, Kyle DE, Martin RK, Oduola AM, Forsyth K, Kemp DJ, Cowman AF 1990. Several alleles of the multidrug-resistance gene are closely linked to chloroquine resistance in Plasmodium falciparum. Nature 345: 255-258.

Fu YX 1997. Statistical tests of neutrality of mutations against population growth, hitchhiking and background selection. Genetics 147: 915-925.

Fu YX, Li WH 1993. Statistical tests of neutrality of mutations. Genetics 133: 693-709.

Le Bras J, Durand R 2003. The mechanisms of resistance to antimalarial drugs in Plasmodium falciparum. Fundam Clin Pharmacol 17: 147-153.

McCutcheon KR, Freese JA, Frean JA, Sharp BL, Markus MB 1999. Two mutations in the multidrug-resistance gene homologue of Plasmodium falciparum, pfmdrl, are not useful predictors of invivo or in-vitro chloroquine resistance in southern Africa. Trans $R$ Soc Trop Med Hyg 93: 300-302.

Mita T, Kaneko A, Hombhanje F, Hwaihwanje I, Takahashi N, Osawa H, Tsukahara T, Masta A, Lum JK, Kobayakawa T, Ishizaki T, Björkman A 2006. Role of $p f m d r 1$ mutations on chloroquine resistance in Plasmodium falciparum isolates with $p f c r t \mathrm{~K} 76 \mathrm{~T}$ from Papua, New Guinea. Acta Trop 98: 137-144.

Mittra P, Vinayak S, Chandawat H, Das MK, Singh N, Biswas S, Dev V, Kumar A, Ansari MA, Sharma YD 2006. Progressive increase in point mutations associated with chloroquine resistance in Plasmodium falciparum isolates from India. J Infect Dis 193: 1304-1312. 
Mixson-Hayden T, Jain V, McCollum AM, Poe A, Nagpal AC, Dash AP, Stiles JK, Udhayakumar V, Singh N 2010. Evidence of selective sweeps in genes conferring resistance to chloroquine and pyrimethamine in Plasmodium falciparum isolates in India. Antimicrob Agents Chemother 54: 997-1006.

Nei M 1987. Molecular evolutionary genetics, Columbia University Press, New York, 512 pp.

Nei M, Gojobori T 1986. Simple methods for estimating the numbers of synonymous and nonsynonymous nucleotide substitutions. Mol Biol Evol 3: 418-426.

Ojurongbe O, Ogungbamigbe TO, Fagbenro-Beyioku AF, Fendel R, Kremsner PG, Kun JF 2007. Rapid detection of Pfcrt and PfmdrI mutations in Plasmodium falciparum isolates by FRET and in vivo response to chloroquine among children from Osogbo, $\mathrm{Ni}$ geria. Malar J 6: 41.

Pati SS, Mishra S, Mohanty S, Mohapatra DN, Sahu PK, Priyadarshi N, Kumar S, Sharma SK, Tyagi PK, Chitnis CE, Das BS 2007. Pfcrt haplotypes and in-vivo chloroquine response in Sundergarh district, Orissa, India. Trans R Soc Trop Med Hyg 101: 650-654.

Póvoa MM, Adagu IS, Oliveira SG, Machado RL, Miles MA, Warhurst DC 1998. Pfmdr1 Asn1042Asp and Asp1246Tyr polymorphisms, thought to be associated with chloroquine resistance, are present in chloroquine-resistant and sensitive Brazilian field isolates of Plasmodium falciparum. Exp Parasitol 88: 64-68.

Ranjit MR, Sahu U, Khatua CR, Mohapatra BN, Acharya AS, Kar SK 2009. Chloroquine-resistant $P$. falciparum parasites and severe malaria in Orissa. Curr Sci 96: 1608-1611.

Reed MB, Saliba KJ, Caruana SR, Kirk K, Cowman AF 2000. Pgh1 modulates sensitivity and resistance to multiple antimalarials in Plasmodium falciparum. Nature 403: 906-909.

Rozas J, Sánchez-DelBarrio JC, Messeguer X, Rozas R 2003. DnaSP, DNA polymorphism analyses by the coalescent and other methods. Bioinformatics 19: 2496-2497.

Sambrook J, Russell DW 2001. Purification of nucleic acids by extraction with phenol: chloroform. Commonly used techniques in molecular cloning. In J Sambrook, DW Russell (eds.), Molecular cloning, appendix 8, volume 3, 3rd ed., Cold Spring Harbor Laboratory Press, New York, p. 7.

Sidhu AB, Verdier-Pinard D, Fidock DA 2002. Chloroquine resistance in Plasmodium falciparum malaria parasites conferred by pfcrt mutations. Science 298: 210-213.
Singh V, Mishra N, Awasthi G, Dash AP, Das A 2009. Why is it important to study malaria epidemiology in India? Trends Parasitol 25: 452-457.

Tajima F 1983. Evolutionary relationship of DNA sequences in finite populations. Genetics 105: 437-460.

Tajima F 1989. Statistical method for testing the neutral mutation hypothesis by DNA polymorphism. Genetics 123: 585-595.

Tamura K, Dudley J, Nei M, Kumar S 2007. MEGA4: Molecular Evolutionary Genetics Analysis (MEGA) software version 4.0. Mol Biol Evol 24: 1596-1599.

Vathsala PG, Pramanik A, Dhanasekaran S, Devi CU, Pillai CR, Subbarao SK, Ghosh SK, Tiwari SN, Sathyanarayan TS, Deshpande PR, Mishra GC, Ranjit MR, Dash AP, Rangarajan PN, Padmanaban G 2004. Widespread occurrence of the Plasmodium falciparum chloroquine resistance transporter $(P f c r t)$ gene haplotype SVMNT in P. falciparum malaria in India. Am J Trop Med Hyg 70: 256-259.

Vinayak S, Mittra P, Sharma YD 2006. Wide variation in microsatellite sequences within each pfcrt mutant haplotype. Mol Biochem Parasitol 147: 101-108.

Volkman S, Wirth D 1998. Functional analysis of $p f m d r 1$ gene of Plasmodium falciparum. Methods Enzymol 292: 174-181.

Watterson GA 1975. On the number of segregating sites in genetical models without recombination. Theor Popul Biol 7: 256-276.

Wellems TE, Panton LJ, Gluzman IY, do Rosario VE, Gwadz RW, Walker-Jonah A, Krogstad DJ 1990. Chloroquine resistance not linked to mdr-like genes in a Plasmodium falciparum cross. $\mathrm{Na}$ ture 345: 253-255.

WHO - World Health Organization 2009. World Malaria Report, WHO, Geneva, 190 pp.

Wilson CM, Serrano AE, Wasley A, Bogenschutz MP, Shankar AH, Wirth DF 1989. Amplification of a gene related to mammalian mdr genes in drug-resistant Plasmodium falciparum. Science 244: 1184-1186.

Wongsrichanalai C, Pickard AL, Wernsdorfer WH, Meshnick SR 2002. Epidemiology of drug-resistant malaria. Lancet Infect Dis 2: $209-218$

Wootton JC, Feng X, Ferdig MT, Cooper RA, Mu J, Baruch DI, Magill AJ, Su XZ 2002. Genetic diversity and chloroquine selective sweeps in Plasmodium falciparum. Nature 418: 320-323.

Zhang LB, Ge S 2007. Multilocus analysis of nucleotide variation and speciation in Oryza officinalis and its close relatives. Mol Biol Evol 24: 769-783. 